\title{
BIBLIOTECAS, CATÁLOGOS E COLEÇÕES
}

\section{LAS BIBLIOTECAS, LOS CATÁLOGOS Y COLECCIONES}

\author{
Amir Brito Cadôr - des@eba.ufmg.br \\ Doutor em Belas Artes pela Universidade Federal de Minas \\ Gerais (UFMG). Professor na UFMG.
}

\begin{abstract}
RESUMO
Introdução: Os livros de artista são o ponto de partida para uma reflexão a respeito de bibliografias contemporâneas, sobre critérios de catalogação dos livros e modos pouco ortodoxos de organização de bibliotecas. Alguns livros de artista são verdadeiras bibliotecas sem paredes, que substituem a lista nominal de livros por imagens de suas capas. Outros livros são catálogos que reproduzem parcialmente as obras.

Objetivo: discutir as relações entre bibliotecas, catálogos e coleções, destacando aspectos da bibliografia material associado a este tipo de obra, com destaque para os paratextos editoriais.

Metodologia: trata-se de uma reflexão teórica acerca dos conceitos de biblioteca, catálogo e coleções.

Resultados: demonstra-se a variedade e a dinâmica conceitual da noção de livro quando aplicada nas diversas nuances das relações entre arte e bibliografia.

Conclusões: indica-se a pluralidade do conceito de livro de artista e sua relação íntima com o conceito de biblioteca.
\end{abstract}

Palavras-chave: Livros de artista. Bibliografia material. Bibliotecas.

\section{INTRODUÇÃO}

Uma característica da arte produzida nas últimas décadas é a ênfase em aspectos metalinguísticos, o desnudamento da estrutura da obra de arte e a consciência histórica do fazer artístico, por vezes apresentada de maneira irônica. Ulises Carrión, um dos primeiros teóricos a escrever a respeito dos livros de artista na década de 1970, diz que os melhores livros de artista são um comentário crítico, implícito ou explícito, a respeito dos livros em geral (2008). Os livros de artista 
podem contribuir para a reflexão a respeito da bibliografia, com destaque para a bibliografia material.

Não é por acaso que o único exemplo conhecido de uma obra de referência que é ao mesmo tempo um catálogo de exposição tem como objeto de estudo os livros de artista. Trata-se de The book on books on artists books, uma bibliografia visual, com curadoria do artista Arnaud Desjardin. Livros de artistas têm sido normalmente vendidos e distribuídos através de pequenas redes de livrarias e galerias que muitas vezes produzem listas de títulos disponíveis em forma impressa. O livro de Desjardin reproduz as capas e páginas internas selecionadas da maioria dos livros apresentados, de modo a dar uma ideia da diversidade de formatos. Os livros são agrupados em seções, de acordo com o tipo ou a finalidade da publicação: catálogos de exposição, obras de referência, inventário de acervos, livros sobre editoras que se dedicam exclusivamente ao assunto, livros de artista que tem como tema os livros de artista, periódicos especializados, catálogos de editoras, catálogo de livreiros, anuários e catálogos de feiras.

Para este artigo, selecionamos alguns livros de artista que tem o próprio livro como tema. Começamos por um grupo de artistas que são também colecionadores de livros. Em uma exposição realizada em 1995 no Cleveland Center for Contemporary Art, o artista e pesquisador Buzz Spector dispôs todos os livros de sua biblioteca em uma única prateleira, em uma sala grande o suficiente para abrigar todos exemplares. A prateleira contornava toda a sala de exposição. Os livros estavam organizados por ordem de tamanho, do maior para o menor. O catálogo da exposição, apropriadamente chamada de Unpacking my library, foi publicado em formato sanfona, de modo que visualizamos uma prateleira extensa repleta de livros. É uma obra autônoma que reproduz a mesma experiência espacial dos visitantes da exposição.

A ordem de tamanho como critério de organização foi adotado pela Coleção Livro de Artista da UFMG para guardar os livros em uma sala na Divisão de Coleções Especiais e Obras Raras, identificados na 
base de dados por um código: E2P5 15 é o décimo quinto livro na prateleira cinco que fica na estante dois. $O$ objetivo é preservar melhor os livros, considerando que o tamanho e o formato das obras muitas vezes fogem dos padrões, com livros muito pequenos (menos de $10 \mathrm{~cm}$ de altura) ou muito grandes (acima de $62 \mathrm{~cm}$ ). Essa disposição na prateleira evita que um exemplar que possui mais de 400 páginas possa estragar outro livro com apenas quatro páginas. Sabemos que se trata de uma prática inviável para grandes coleções, mas que é possível em um acervo de até três mil exemplares, com acesso restrito aos bibliotecários. Os usuários não têm acesso às estantes, é uma norma que se aplica a todo o setor.

\section{DISCUSSÃO}

As formas particulares de organizar os livros, ou deixá-los desarrumados, é um assunto que interessa a pessoas que possuem uma grande quantidade deles. Em Stored images (1992), do artista, editor e colecionador de livros de artista Maurizio Nannucci, podemos conhecer não apenas uma biblioteca, mas vinte e uma. A capa mostra 21 fotografias amontoadas, as mesmas que aparecem no interior do livro, como se fossem livros empilhados. No centro de cada página, uma fotografia do interior de uma livraria especializada em livros de artista, mostrando principalmente as prateleiras lotadas e os livros amontoados nos depósitos. São lugares que o artista visitou e onde ele provavelmente comprou exemplares para sua coleção, incluindo a Art Metropole, de Toronto, a Printed Matter, de Nova lorque e a Walther Konig, de Colônia, entre outras livrarias. Ao mostrar as estantes, o artista faz um comentário sobre os diferentes critérios de organização e também sobre a distância entre o mundo idealizado pela teoria, que categoriza e separa os itens e a realidade material do espaço disponível para acomodar os livros, que junta no mesmo espaço itens que são conceitualmente distantes. 
O livro Cover Version (2004), de Jonathan Monk, consiste em fotografias das capas de livros de artista de sua coleção pessoal, apenas uma capa por página, mostrada no lado reto da folha, de modo que as capas reproduzidas ocupem a mesma posição que ocupam em relação ao livro, à direita da lombada. As imagens foram impressas em um papel que é revestido em apenas um dos lados, como se um conjunto de capas fossem grampeadas para formar um único volume. As páginas são numeradas, e por isso percebemos que a repetição de uma mesma imagem não é um erro. Olhando com atenção, vemos que se trata de três exemplares da mesma obra, com pequenas diferenças entre eles devido ao uso. Muitos colecionadores de livros costumam guardar exemplares repetidos, seja para trocar com outros colecionadores, seja por medo de que um exemplar emprestado não seja devolvido. O bibliotecário Clive Phillpot, que foi diretor da biblioteca do Museu de Arte Moderna de Nova Iorque, a primeira biblioteca institucional com uma política de aquisição de livros de artista, defendia que uma situação ideal é possuir três exemplares do mesmo livro, um para consulta, outro para exposição, outro para o arquivo.

Um livro mostrando apenas as capas é muito impessoal. Baseada na obra de Monk, a artista Amanda Andersen resolveu publicar um inventário de sua coleção. Ao invés de uma lista com os títulos e autores, preferiu mostrar imagens dos livros, de modo que cada página de Page Count corresponde a uma página de um livro de sua biblioteca. Com isso, ela demonstra a arbitrariedade de todo critério de seleção, inclusive dos critérios utilizados para definir os livros que devem ou não fazer parte de uma determinada biblioteca.

Alguns artistas possuem coleções que se tornaram notáveis. Conhecido por suas fotografias de cowboy que ilustravam campanhas publicitárias do cigarro Marlboro, o artista norte-americano Richard Prince é um apaixonado por livros e um colecionador de obras literárias da cultura pop norte-americana (ficção científica, romances eróticos e outros tipos de livro comumente desprezados pelas bibliotecas públicas) 
e das contraculturas dos anos 1950 até os anos 1980, especialmente obras de autores beat, hippie ou punk. Por ser um reconhecido especialista no assunto, Richard Prince foi convidado a fazer a curadoria da exposição American Prayer na Bibliothèque Nationale de France e apresentar pela primeira vez ao público parte de sua famosa coleção. $O$ título da mostra foi tirado de um poema de Jim Morrison, que ao lado de Bob Dylan e The Velvet Underground, é uma referência para o artista. Prince também se interessa por autores conhecidos como junkies e os chamados malditos - manuscritos de Rimbaud, Céline, Cocteau e Genet, revistas underground e livros populares foram selecionados entre coleções da FBN que permaneciam distantes do grande público alguns livros eróticos publicados no início do século $X X$ e que influenciaram o grupo surrealista nunca haviam sido retirados para empréstimo. Documentos relacionados com os ícones da geração beat foram apresentados, como uma cópia de Naked Lunch anotada por William Burroughs, ou o rolo de papel manuscrito de On the road, de Jack Kerouac. A coleção de Prince é a maior reunião de edições do livro Lolita de Nabokov, em cerca de vinte línguas, incluindo a raríssima primeira edição anotada pelo autor.

O ponto de partida para a exposição surgiu quase uma década antes, com a publicação de American English em 2003. Neste livro de artista, Richard Prince compara as primeiras edições de romances populares publicados nos Estados Unidos com seus equivalentes britânicos, em uma espécie de história cultural contada do ponto de vista de um artista. As capas das edições americanas destacam-se das versões britânicas, mais contidas, revelando diferentes facetas de uma época. Ao invés do fundo neutro, geralmente usado nesse tipo de registro, foram usados outros livros e detalhes de obras do próprio artista.

A rede de citações de que é feita a literatura e as artes visuais serviram de ponto de partida para La Bibliothèque Fantastique, um projeto artístico de Antoine Lefebvre. Os livros são gratuitos e 
disponíveis para download na internet para que o leitor possa imprimilos em casa. A maioria dos livros são produções exclusivas, enquanto outros são reedições de obras que estão livres de qualquer tipo de direitos. O objetivo da LBF é oferecer uma visão sobre os livros expressa pelos próprios livros. Os trabalhos são feitos de excertos de outras obras, como se as páginas, frases e palavras se encontrassem em um golpe de sorte. Les mots et les choses, por exemplo, é a combinação das capas do livro Les Mots, de Jean Paul Sartre, com Les Choses, de Georges Pérec, formando o título de um famoso livro do filósofo Michel Foucault.

As capas dos livros LBF são, invariavelmente, apropriações de fontes existentes. O nome do autor é eliminado e substituído pelo nome do artista, o nome do editor original também é apagado, uma vez que o novo livro já não é sua propriedade. $O$ artista também pode alterar 0 título do livro para melhorá-lo. O nome do projeto remete a um texto de Michel Foucault sobre A tentação de Santo Antão, de Gustave Flaubert, um autor que considerava a literatura como um produto das bibliotecas.

\section{REFLEXÕES CONCLUSIVAS}

Para muitos colecionadores de livros, um exemplar que pertenceu a uma biblioteca é inaceitável. São livros desgastados pelo uso, carimbados, com restos de fita adesiva na capa e muitas vezes ainda possuem um bolso colado às folhas de guarda para o cartão de empréstimo. Os livros têm sido frequentemente danificados pelos patronos da biblioteca, que deixam diversas marcas de propriedade em cada exemplar. É preciso escolher qual página devo estragar para colar minha etiqueta. Mas será que é necessário colocar marcas de propriedade em obras que têm acesso restrito e controlado? Depois de descartados pela biblioteca e comprados pelo colecionador, sempre existe a dúvida sobre o que é pior, mostrar o número de chamada da biblioteca ou a cicatriz de sua remoção. Sara MacKillop compila em Ex- 
library book os restos e as marcas da ação dos bibliotecários ao lado de diagramas e imagens ligadas a sistemas de bibliotecas.

Um livro de artista pode ser ao mesmo tempo um inventário, uma lista de desejos, uma paródia, um catálogo de uma exposição não realizada? A Night Visit to the Library é um projeto pessoal realizado em 2012. A ideia para o livro surgiu de uma obra de Endre Tót que mostrava apenas as silhuetas das pinturas, imitando um guia de museu ( $A$ Night Visit to the National Gallery, 1975). As silhuetas das capas foram reduzidas proporcionalmente, de modo que podemos comparar os livros pelo formato e tamanho. As figuras estão ainhadas pela linha de base, como se estivessem em uma prateleira. As legendas identificam cada obra, e permitem observar os critérios adotados ao escolher determinados livros: aproximações dadas pelo título, pelo formato, local e ano de publicação. Uma página interrompe o fluxo de leitura e apresenta os livros como se fosse um catálogo de editora. A leitura atenta das legendas revela que alguns livros estão reproduzidos na escala 1:1, provocando um estranhamento, como se a fronteira entre representação e apresentação por um instante fosse destruída. André Malraux dizia que os livros com reproduções fotográficas de obras de arte são como museus sem paredes. Um livro de artista também pode ser uma biblioteca sem paredes.

\section{REFERÊNCIAS}

ANDERSEN, Amanda. Page count. Berlin: Shot Put, 2011.

FONTAINE, Claire. Vivre, vaincre. Paris: Dilecta, 2009.

CARRIÓN, Ulises. Quant aux livres/ On Book. Geneve: Éditions Héros-Limite, 2008.

GIBBS, Michael. Selected pages. Amsterdam: Kontexts, 1978.

LEFEBVRE, Antoine. Les mots et les choses. Paris: La Bibliothèque Fantastique, 2010. 
LUTZ, Andres; GUGGISBERG, Anders. Das grosse buch der strunke. Zurich: Nieves, 2012.

MACKILLOP, Sara. Ex-library book. Copenhagen: Pork Salad Press, 2012.

MATTHÉ, Jan. Katalog 1. Antwerp: Für Dich Verlag, 2011.

MONK, Jonathan. The project book project. Bristol: Arnolfini, 2003.

NANNUCCI, Maurizio. Stored images. Bolzano: Museo d'Arte Moderna, 1992.

PHILLPOT, Clive. Booktrek: selected essays on artists' books (19722010). Zurich: JRP Ringier, 2013.

PRINCE, Richard. American english. Köln: Walther König, 2003.

RUBIN, Robert (Ed.). Richard Prince: American Prayer. New Yor: Gagosian Gallery, 2011.

SPECTOR, Buzz. Unpacking my library. Cleveland: Cleveland Center for Contemporary Art, 1995.

\section{Title}

Libraries, catalogs and collections

\section{ABSTRACT}

Introduction: Artist books are the starting point for a reflection on contemporary bibliographies on cataloging criteria of books and ways of organizing libraries. Some artists' books are true libraries without walls, replacing the nominal list of books by images of their covers. Other books are books that partially reproduce the works.

Objective: To discuss the relationship between libraries, catalogs and collections, highlighting aspects material literature associated with this type of work, especially the editorial paratexts.

Methodology: it is a theoretical reflection about the library concepts, catalog and collections.

Results: depicts the variety and dynamics of the conceptual notion book when applied in the various nuances of the relationship between art and books in context of libraries.

Conclusions: indicates the plurality of the concept of artist's book and its close relationship with the concept of library.

Keywords: Artist books. Material bibliography. Libraries 


\section{Titulo}

Las Bibliotecas, los Catálogos y Colecciones

\section{Resumen}

Introducción: libros de artista son el punto de partida para una reflexión sobre bibliografías contemporáneos sobre catalogación criterios de libros y maneras poco ortodoxas de la organización de las bibliotecas. Algunos libros de artista son verdaderas bibliotecas sin paredes, en sustitución de la lista nominal de los libros por las imágenes de sus portadas. Otros libros son libros que reproducen parcialmente las obras.

Objetivo: analizar la relación entre las bibliotecas, los catálogos y colecciones, destacando aspectos literatura material asociado a este tipo de trabajo, especialmente los paratextos editoriales.

Metodología: se trata de una reflexión teórica sobre los conceptos de biblioteca, catálogo y colecciones.

Resultados: representa la variedad y la dinámica del libro noción conceptual cuando se aplica en los diferentes matices de la relación entre el arte y la literatura.

Conclusiones: indica la pluralidad del concepto de libro de artista y su estrecha relación con el concepto de biblioteca.

Palabras clave: Libros de artista. Bibliografía material. Bibliotecas.

Recebido em: Abril de 2015

Aceito em: Julho de 2015 